\title{
Boundary issues: employing patients as staff?
}

\section{CASE 1}

$\mathrm{Mr}$ and Mrs Smith had been registered with the practice for over 10 years. Mr Smith started working in the practice office approximately 4 years ago. Mrs Smith developed emotional problems and became depressed, which necessitated a referral to the local psychiatric team. It transpired that there were marital difficulties and Mrs Smith had an affair which her husband was unaware of. The thought of her husband having access to the clinical correspondence from the psychiatric team was of great concern to Mrs Smith and also her GP. Elaborate methods were put into place to avoid clinical correspondence passing through Mr Smith's hands.

\section{CASE 2}

John's father is a GP, and John has been registered at his father's practice since birth. John had felt anxious and was taking illegal drugs. His parents had separated 6 months ago and were not on speaking terms. John did not want details about his family relationships covered in the correspondence from the local drug service.

\section{CASE 3}

Kim had been registered with her GP for many years. She suffers with bipolar disorder. Kim's behaviour has at times been challenging. Kim's mother worked at the practice as a receptionist. It was difficult to manage Kim with her mother working in the practice.

\section{CASE 4}

$\mathrm{Mr}$ Jones was a practice manager. His wife died suddenly and he found it difficult to adjust. He then became suicidal and needed to be referred to the local psychiatric team. Mr Jones had been registered with the practice where he worked for many years. He didn't want any correspondence from the psychiatric team to be sent to the practice.

$$
\text { ***** }
$$

The case scenarios above give examples of how difficult it can be to look after relatives or colleagues/employees registered at the same surgery. Although most doctors are aware of this, it is still common practice to have relatives and/or employed staff registered in the same surgery in certain areas of the country. It is particularly common in rural or semirural general practices. Employees are often local residents and will not be within the geographical boundaries of the neighbouring practices. Patients who have been registered with the practice for many years may apply for job vacancies when they arise seeing it as a local and convenient option. Others may see it as a route to accessing an 'enhanced' service from their GP as they imagine themselves becoming 'special' patients, with instant access to their GP.

Employees may be registered with a GP for many years before any significant issues arise. Situations can suddenly arise where there are significant boundary issues and it can then become very difficult to deal with the situation. The patient/relative/employee is often at that time distressed and in need of support. GPs find themselves trying to provide appropriate care for their patient while at the same time safeguarding confidentiality issues. This often means ensuring other employees at the practice do not have access to the patient's records or opening the post. There is also the issue of providing optimum care to someone that GPs may have a closer personal relationship with than their average patient. Furthermore, it is important to realise that it is not just the employee's confidentiality at stake but also that of their family.

We have both encountered difficult situations with regard to patients as colleagues/employees and confidentiality. For example, GP partners may have personal knowledge of employees that could negatively affect their chances of promotion. Requests not to document certain facts in a patient's medical records and not to have correspondence sent to the practice have both occurred. Also, confidential information regarding lifestyle choices, marital/relationship issues, mental health problems, and significant diagnoses in clinical correspondence from third parties can be difficult to shield from office staff. These employees are often those who open the post and enter these letters onto patient's medical records.

Guidelines appear to be non-existent. We approached the Royal College of General Practitioners who directed us to the Rural and Remote Practice Group. They acknowledged the issues arising from this subject and said their members encounter them on a regular basis. They advise that 'employees be encouraged to register with another practice if geographically possible', but accepted that this may not always be possible. We also consulted the Medical Defence Union and the Medical Protection

\section{Box 1. Suggestions to reduce boundary issues.}

- Avoid your relatives being registered at the practice where you work. Even if they are looked after by a colleague, there is still ample scope for boundary issues.

- Avoid working and being registered at the same practice. If possible make this a condition of employment which should be arranged at the time of appointment.

- Should the prospective staff member and any family members registered as patients be informed in writing of the risk of 'breaches of confidentiality'?

- If unavoidable, then prospective staff members and their relatives should be informed in writing of the risk of 'breaches of confidentiality'.

In a rural setting, try to make a reciprocal arrangement with your nearest practice so that employees of your practice can register with them and vice versa. 


\section{Nita's revenge}

Society. Neither was aware of any specific guidelines and directed us to the GMC's advice on patient confidentiality, for general principles. The GMC have provided some helpful recommendations, ${ }^{1}$ suggesting that provision of medical care to people with which you have a close personal relationship should be avoided. However, there do not appear to be any specific guidelines regarding employing patients as staff in general practice.

We felt it was important to raise awareness of this issue. It is clear from a number of conversations that we have had with colleagues that the practice of employing patients as staff is still widespread with all its associated problems. It would therefore make sense to prevent these situations from happening if at all possible. The geographical issue is an important one. While it may be easy for a future employee to register with a different practice around the corner if you live in an urban setting, this may be much harder to do in a rural setting. Nevertheless it is important to try to prevent boundary issues if possible. We have made a number of recommendations that could avoid such issues (Box 1), and we hope they will generate a greater awareness and further discussion.

\section{Kate Salmon and Marinus Klijnsma}

\section{REFERENCE}

1. General Medical Council. Good medical practice. Manchester: GMC, 2006. http://www.gmcuk.org/guidance/good_medical_practice/GMC_GMP .pdf (accessed 8 Dec 2008)

DOI: 10.3399/bjgp09X394932
I popped into Lily's bar for my sun downer. My friend Ben, artist and strandloper resplendent in his beaded Pondo jacket and red bandana, was looking a bit shook up - not his usual diffident persona. As we gazed at the Indian Ocean surf-line, ginpink tinted in the fading light, his voice rasped 'I almost died yesterday'. 'Tell me about it', I said thinking about maybe how he could have fallen off the steep path to his forge above the cliff, having yet again consumed too much red wine. "I saw this mushroom, about 8 inches wide on a bank near my place. I gingerly recovered it and put it in the pan. It was the most delicious mushroom that I ever tasted. About 30 minutes later, I was troubled at both ends, spewing out. I saw my neighbours as if going to work in the wrong direction when in fact they were returning homewards. I went into a deep sleep and work up in the darkest night.'

'I checked out the mushroom today - in fact it was Amanita pantherina, one of the death cup family. The last ones I saw here were about 20 years ago - that's why I didn't examine the mushroom carefully. I definitely didn't hallucinate. You know that the bog men used to give their human sacrificial offerings Amanita pantherina and the Incas gave them peyote before dispatching them. They went to their fates, grinning - on a happy trip to perdition. The other variety is used as the fly agarics. You take a piece of mushroom in a bowl of milk and the flies congregate and die. There's a volcano of them after a while.' We filled our glasses again with red wine, toasted his recovery, and trusted that it would detoxify his system of phallotoxin, even if the evidence for efficacy was lacking.

I recalled a medical genius who had to figure out, during the Second World War, why there was an epidemic of a mysterious illness in an infantry division in Poland. Men were being violently ill and out of action for a couple of weeks. Being an epidemiologist, he made a list of time, place, and personal characteristics. No common pattern emerged. He then called for a list of names of those affected. They were practically all Italian. Quickly excluding all infectious and familial syndromes, he deduced that it may be dietary. Inspiration - they could all like mushroom in the autumn. End of outbreak.

We proceeded to debate the merits of having to ingest substances to enter the mysteries of other cultures. Robert Pirsig in Lila: an inquiry into Morals, ${ }^{1}$ argued one needed to ingest peyote to truly understand the religiosity of Native American culture. We decided that imbibing alcohol was sufficient for Western and Pondo culture. We toasted James Joyce and Dylan Thomas for their cultural use of whiskey and porter. I gave a rendition of Finnegans Wake. We decided on a party list to include our aforementioned western idols and their characters of Timothy Danaos and Dona Ferentes with food cooked by Nita Phalloides. I made a mental note to politely decline vegetarian meals by artists. However, I'm still open to artistic meals by vegetarians.

\section{Don O'Mahony}

\section{REFERENCE}

1. Pirsig R. Lila: An Inquiry into Morals. New York: Bantam Books, 1991.

DOI: 10.3399/bjgp09X394941 